\title{
El cultivo del trigo en Nueva Galicia durante el siglo xvII
}

\section{Wheat Production in 17th Century Nueva Galicia}

\author{
C. René de León Meza \\ Departamento de Ciencias Sociales y Jurídicas \\ CUCEA, Universidad de Guadalajara \\ leonmeza@yahoo.com
}

\begin{abstract}
Resumen
Este artículo estudia los factores que determinaron el desarrollo y consolidación del cultivo del trigo en varias comarcas del reino de Nueva Galicia durante el siglo xvir tomando como referencia la última fundación de Guadalajara. Destaca lo vital que fue para esta industria la mano de obra indígena a través del sistema de repartimiento forzado y la vigencia de este hasta el siglo XviII en contraste con Nueva España donde fue suprimido desde 1633. La hipótesis aquí planteada es que la escasez de trigo y harina que constantemente sufrieron los habitantes de la ciudad de Guadalajara se debió a la confabulación de las autoridades del Cabildo con los comerciantes y productores para acapararlos, esconderlos y luego venderlos a precios elevados. La política que los regidores implementaron de no instalar una alhóndiga que concentrara y regulara la venta de esos productos confirma el anterior aserto.
\end{abstract}

Palabras clave: trigo; indios; repartimiento; haciendas; alimentación.

\section{Abstract}

The article studies the factors that determined the development and consolidation of wheat production in various districts of the New Kingdom of Galicia in the 17th century, using the most recent founding of Guadalajara as a reference. It highlights the crucial role played by indigenous labor in this industry, through the forced labor system, which remained in place until the 18th century, unlike New Spain, where it was abolished in 1633. This paper hypothesizes that the shortage of wheat and flour experienced by the inhabitants of the city of Guadalajara was due to collusion between the town's council and merchants and producers, which involved hoarding and concealing these materials and subsequently selling them at high prices. The policy implemented by the governors, of not creating a corn exchange to concentrate and regulate the sale of these products, confirms this statement.

Key words: wheat; Indies; forced labor; haciendas; food.

Fecha de recepción: 1 de abril de 2014 Fecha de aceptación: 22 de julio de 2014

Secuencia, ISSN 0186-0348, núm. 94 | enero-abril de 2016 | pp.39-76 


\title{
El cultivo del trigo en Nueva Galicia durante el siglo XVII
}

\author{
C. René de León Meza
}

\section{INTRODUCCIÓN}

\begin{abstract}
Ona uando terminó el proceso de conquista iniciado por Nuño Beltrán de Guzmán en 1532, los habitantes europeos de las recién fundadas villas de Guadalajara, Compostela, Chiametla, Purificación y San Miguel de Culiacán sufrieron el desabasto de víveres (en particular del trigo) debido a que todavía no se introducía su cultivo a esas áreas. Tenían que traerlo desde la ciudad de México ofreciendo a cambio los bienes que les tributaban los indígenas (Pacheco y Cárdenas, 1865, vol. XIV, pp. 83-95). Los conquistadores intentaron que los indios sembraran ese cereal imponiéndoselo como pago de tributo pero no tuvieron éxito porque para estos les representaba más trabajo, mayor inversión y rendía menos que el maíz, además de que prevalecía la tradición, el gusto y preferencia por este último (Borah, 1994, pp. 87-88).

A lo largo de la segunda mitad del siglo xvi sólo un número reducido de pueblos de indios que estaban directamente administrados por la corona (Tequila, Los Guajes, San Francisco, Ahuacatlán, Amasaque, Suchil y Tepic) pagaron parte de sus tributos con trigo, pero las cantidades de este siempre fueron muy magras (Borah, 1994, pp. 151-243). De 29 años que se tienen registrados para este periodo (1555-1586), la corona recibió apenas 1353.6 fanegas con una notable tendencia a la baja en los últimos once años, donde sólo los habitantes de Tequila permanecieron pagando once fanegas al año (Borah, 1994, p. 288). A partir de 1587 ya no aparecerá más en el pago de tributo de pueblos sujetos a la corona. Falta conocer si los pueblos que estaban encomendados a particulares lo cultivaron; hasta el momento no hay pruebas documentales conocidas que lo confirmen.

Lo que ocurrió entonces fue que algunos españoles se vieron obligados a dedicarse a la agricultura del trigo sustentándola en la fuerza de trabajo indígena, logrando en poco tiempo que la siembra de esta sémola estuviera presente en varias regiones de Nueva Galicia. En algunas de ellas (Ameca) se dio un proceso cuya característica inicial fue una producción intensiva que
\end{abstract}

\section{(ㅇ)(1) $\$$}


posteriormente fue disminuyendo considerablemente ${ }^{1}$ hasta darse casos en donde se dejó de sembrarlo (Santa María de los Lagos y Aguascalientes). ${ }^{2}$ En otras regiones el cultivo del trigo se consolidó y permaneció vigente durante toda la época colonial.

Lo que este artículo pretende es analizar los factores que influyeron para que en una amplia región de Nueva Galicia -cuyo epicentro fue la ciudad de Guadalajara- se diera una consolidación y especialización en el cultivo del trigo. Para ello es fundamental tomar como punto de partida la cuarta y última fundación de esa ciudad ocurrida en 1542, justo después de sofocada la gran rebelión indígena conocida como la de El Mixtón. Las autoridades reales encabezadas por el virrey Antonio de Mendoza la planearon para convertirse en el asiento poblacional más importante y seguro del norte novohispano. Con el fin de evitar nuevos alzamientos se fundaron en torno a ella un conjunto de pueblos habitados por los indios recién derrotados. Fue ubicada en un valle (Atemajac) rodeado de tierras fértiles donde podría desarrollarse el cultivo del trigo y donde existían además numerosos pueblos de indios que asegurarían la mano de obra que se requiriera.

A la importancia estratégica de Guadalajara se sumó la relevancia económica que alcanzó en pocos años al convertirse en un espacio concentrador y redistribuidor de mercancías con las que se abastecía a todo el reino y a las provincias de Sinaloa, Sonora y Nueva Vizcaya. Gracias a ello y a las bondades de su clima fue nombrada en 1560 capital del reino y sede de obispado. Lo anterior permitió a la ciudad gozar de una serie de privilegios destinados a asegurar el suministro de uno de los alimentos básicos de su población española, el trigo.

Estudiando el funcionamiento del cultivo del trigo en un grupo de haciendas que se ubicaban dentro de un área que no pasaba de los 90 kilómetros de Guadalajara, podremos entender cómo las políticas implementadas por las autoridades de la audiencia de ese reino facilitaron el desarrollo y consolidación de esa actividad agrícola. El mayor ejemplo de estas fue la larga

${ }^{1}$ La descripción geográfica del pueblo de Ameca escrita en 1579 menciona cómo en la ribera de su río había diez o doce labores de trigo en las que se sembraban 500 fanegas de sembradura, añadiendo que en años pasados se sembraba mucho más pero debido a la disminución de los indios que la trabajaban ya no ocurría así, ocasionando que de ocho labradores que había, sólo quedaran tres (Acuña, 1988, pp. 43-44).

${ }^{2}$ Según el obispo de Guadalajara Alonso de la Mota y Escobar, cuando recién se fundaron las villas de Santa María de los Lagos y Aguascalientes sus habitantes se dedicaron a la siembra de trigo y maíz, pero tiempo después la abandonaron para criar exclusivamente animales, teniendo que importar los granos para su alimentación (Mota, 1993, pp. 32-58).

\section{(ㅇ)(1) $\$$}


permanencia del sistema de repartimiento forzado de mano de obra indígena que aseguraba a los hacendados que sembraban el trigo recibir dos veces al año trabajadores indios para que realizaran las distintas labores que ese cultivo requería. Esto a pesar de que ese sistema había sido abolido en otras áreas de la Nueva España desde 1633, mientras que en Nueva Galicia continuaba vigente todavía en el primer tercio del siglo xviII. También las facilidades con que se concesionaba la saca de agua de mantos acuíferos para regar los trigales y los intentos para que pueblos de indios lo sembraran a cambio de exentarlos de la obligación de enviar mano de obra fomentaron su cultivo.

A pesar de estas acciones, los habitantes de la ciudad de Guadalajara padecieron a lo largo del siglo xvir la escasez de trigo o harina y sus altos precios. Algunos testigos de la época creían encontrar el origen de este mal en las condiciones climáticas y pobreza de las tierras pero no fue así. La hipótesis central de este artículo es que la producción conjunta de todas las haciendas sobrepasaba las necesidades de los consumidores. La esencia de la escasez radicaba en el acaparamiento de granos por parte de los hacendados y comerciantes, así como la corrupción de los miembros del Ayuntamiento de Guadalajara, quienes aparentaban tomar medidas para asegurar el abasto de esta sémola y regular los precios de venta de la harina o pan a través de numerosas ordenanzas, pero en la práctica solapaban la regatonería.

A pesar de que la bibliografía de Nueva Galicia para el siglo xvir es rica en trabajos de análisis y compilaciones documentales, considero que es un periodo que falta mucho por estudiar. ${ }^{3}$ Tan sólo en el rubro de la agricultura desconocemos la historia de muchos cultivos como el de la caña de azúcar, la cebada, el maíz, frijol, chile y trigo. En el caso de este último, los autores antes citados han aportado valiosa información sobre algún aspecto en específico de su cultivo, pero no hacen una historia del mismo. Por ejemplo, los profesores Moisés González Navarro y Águeda Jiménez Pelayo cuando analizan por separado la importancia del sistema de repartimiento de mano de obra indígena en Nueva Galicia, coinciden al concluir que el cultivo del trigo

${ }^{3}$ Las obras más destacadas que han estudiado totalmente o parte del siglo xvir son las realizadas por Thomas Calvo (1992), Peter Bakewell (1984), Águeda Jiménez Pelayo (1989), Jean Pierre Berthe (1994), Domingo Lázaro de Arregui (1980), Alonso de la Mota y Escobar (1993), Moisés González Navarro (1953), Eric Van Young (1989), José F. de la Peña (1983), Jesús Gómez Serrano (2006), Juan B. Iguíniz (1971), Claudio Jiménez Vizcarra (1978), Ricardo Lancaster Jones (1974), Michel Mathes (1976), Fray Antonio Tello (1968). Al final del artículo viene la bibliografía de estos trabajos.

\section{(이요 $\circledast$}


fue el que más se benefició de este tipo de trabajadores al recibir muchos más que cualquier otra industria (González, 1953; Jiménez, 1989). ${ }^{4}$

El profesor Van Young, cuando realizó su investigación sobre la economía rural en Guadalajara a partir del último tercio del siglo Xvir hasta fin de la época colonial, analizó la importancia del trigo como alimento para los habitantes de esa ciudad, centrándose en la relevancia de la mano de obra de los indios y en las cantidades que de estos se enviaban a trabajar en su cultivo y cosecha (Van Young, 1989). Para lo anterior se basó en los datos de la obra de González Navarro antes citada. Es importante señalar que cuando ambos autores realizaron su análisis sobre ese último periodo del siglo XVII, no incluyeron registros de 21 años de repartimientos indios para el cultivo del trigo. Esto se debió a que no se sabía de la existencia de ellos. Cuando se reorganizaron los fondos documentales del Archivo de Instrumentos Públicos de Guadalajara, apareció información que incluye los años de 1668, 1678-1687 y $1690-1699 .{ }^{5}$

Estos nuevos datos combinados con otras fuentes cualitativas me permiten hacer un análisis más completo sobre la historia del cultivo del trigo en el siglo xvir. Coincido con los anteriores autores en cuanto a la dependencia que tuvo la siembra y cosecha de este cereal de la mano de obra indígena, pero me aparto y difiero en algunas de sus conclusiones y reflexiones, en particular de la del profesor Van Young (1989, p. 249), cuando plantea la idea de que en el siglo XVII son escasos los registros de repartimiento en Nueva Galicia y que la documentación empieza a abundar alrededor de 1685, cuando la institución ya estaba moribunda. La anterior sentencia no tiene fundamento pues existen numerosos registros de repartimientos de indios desde 1620. De ninguna manera este sistema laboral estaba moribundo, justo en la década de los ochenta de aquel siglo fue cuando se dieron las mayores asignaciones de mano de obra, en particular los años de 1688 y 1689.

Si en el decenio siguiente el registro de indios repartidos disminuyó considerablemente, no significó que el sistema estuviera moribundo o fuera una señal de la desaparición del mismo como lo afirmó Van Young. Se debió, en

${ }^{4}$ González Navarro (1953) se centra en el último tercio del siglo xvir y la primera mitad del XVIII, en cambio Águeda Jiménez (1989) incluye muchos años de la primera mitad del XVII.

${ }^{5}$ La documentación relativa a la asignación de mano de obra indígena de repartimiento se encuentra en los libros de gobierno de la Real Audiencia de Guadalajara que resguarda el Archivo de Instrumentos Públicos de Guadalajara. Desconozco por qué motivos están ahí pues pertenecen al archivo de la Real Audiencia de Guadalajara que está bajo el cuidado de la Biblioteca Pública del Estado de Jalisco.

\section{(ㅇ)(1) $\$$}


esencia, a la situación administrativa que vivieron algunas haciendas en esos años. En la de Los Cuisillos, su dueño comenzó a tener serios problemas económicos a partir de 1692. Esta le fue embargada y pasó a ser administrada por uno de sus acreedores, pero aun así continuó recibiendo indios hasta 1694. Al año siguiente, el dueño de la hacienda solicitó recuperar la administración de la misma, alegando la ruina en la que la tenían los administradores. Este pleito se prolongó durante varios años en los que coincidentemente no hay registros de repartimientos a esa hacienda. Pero cuando se regularizó la propiedad de ella en 1703, continuó recibiendo indios hasta 1730. Algo parecido debió haber sucedido con las haciendas de Los Cedros ubicada en la jurisdicción de La Barca y la de Toluquilla al sur de Guadalajara. De ellas existen pocos registros en los últimos años del siglo XVII, pero durante los primeros 30 años del XVIII sus asignaciones se vuelven a normalizar, recibiendo las mismas cantidades que antes, lo que demuestra la vigencia de este sistema de repartimiento.

Otro investigador que también ha analizado algunos aspectos del cultivo del trigo en Nueva Galicia durante el siglo xvil es Thomas Calvo en su tesis de doctorado presentada en $1987 .^{6}$ Él esboza una geografía del trigo en Nueva Galicia, aportando algunos datos sobre el rendimiento de este cereal y el acaparamiento que hacen unos cuantos personajes de la ciudad. El profesor Calvo plantea la idea que desde el primer tercio del siglo XviI "el cereal blanco" de Guadalajara vive una época de eclipse por la desaparición de algunos "señores cerealeros". Agrega que en la segunda mitad del siglo existe una carencia de molinos de trigo y se pregunta entonces si la época de oro de ese cereal habría ya desaparecido (Calvo, 1992a, pp. 200-201 y 276-277). Por el alto número de trabajadores asignados a las haciendas trigueras en la segunda mitad de esa centuria y por los inventarios de muchas de ellas en donde aparecen siempre molinos de trigo, me aparto de la idea expresada por este autor. En todo caso hace falta realizar un estudio sobre la evolución de los montos de producción de este grano durante el siglo xvir.

Este artículo está sustentado en la información proveniente de los Libros de Gobierno de la Real Audiencia de Guadalajara, que contienen los repartimientos de indios que se otorgaban a los propietarios de haciendas y ranchos. Las Actas de Cabildos de la ciudad de Guadalajara aportaron da-

${ }^{6}$ La tesis llevó por título Guadalajara, Capitale provinciale de l'Occident mexicain au XviIe siècle (1987). Ecole des Autes Etudes en Sciences Sociales, París. Los libros que se han publicado a partir de ella son Guadalajara y su región en el siglo xvir. Población y economía (1992a); Poder, religión y sociedad en la Guadalajara del siglo XVII (1992b); y Por los caminos de Nueva Galicia: transportes y transportistas en el siglo XVII (1997).

\section{(ㅇ)(1) $\$$}


tos importantes sobre las constantes necesidades de harina que padecían los habitantes de ella y las acciones que tomaron sus funcionarios para remediarlas. Los libros de Notarios, así como los de Tierras y Aguas, brindaron información valiosa para comprender la infraestructura de las haciendas trigueras, sus problemáticas y en algunos casos su producción y rendimiento. Fueron de gran utilidad, también, las diversas descripciones geográficas realizadas en los siglos XVI y XVII.

\section{CULTIVO Y COSECHA DEL TRIGO}

Las características climatológicas de Nueva Galicia limitaron los tiempos y lugares de la siembra de trigo. La temperatura cálida en la mayor parte del territorio determinó que muy pocas áreas tuvieran las condiciones óptimas para el cultivo de esa sémola: un clima de frío a templado, abundancia de agua, tierras fértiles y, por supuesto, mano de obra segura para las labores agrícolas. La geografía neogallega configuró dos zonas que se especializaron en la siembra y cultivo de este grano. Una hacia el norte, ubicada en la parte más alejada de la capital del reino, en donde destacaron tres importantes pueblos cultivadores de esa semilla: Jerez, Tlaltenango y Juchipila. La otra zona, que es la que aquí se estudia, formaba un semicírculo con un radio no mayor de 90 kilómetros alrededor de Guadalajara, destacando las labores que se encontraban en las jurisdicciones de Tlajomulco, Tala, La Barca, Tlacotán, San Cristóbal de la Barranca, Etzatlán, Cocula, Colimilla y Matatán.

Se sembraba una vez al año mediante el sistema de riego; no se hacía en el de temporal porque las lluvias comenzaban hasta fines de junio y porque en octubre caían heladas y el trigo, que apenas iba creciendo, se quemaba. La humedad y el calor generados por los aguaceros hacían que crecieran abundantes matorrales que cubrían a las espigas y las ahogaban. Por más escardas que se realizaran, estos volvían a nacer y crecer rápidamente. Además, las aguas de temporal provocaban que el trigo se hiciera prieto y añublado (infectado por el hongo añublo) mientras que el de riego salía blanco y de muy buena calidad.

Un problema generado por el aire húmedo de la región fue el poco tiempo que se conservaba el trigo. Varios cronistas, como Juan López de Velasco (1971, p. 134) a fines del siglo XVI, Alonso de la Mota y Escobar y Domingo Lázaro de Arregui (1980, pp. 81-82), coincidieron en sus observaciones sobre el poco tiempo que duraba el grano en Nueva Galicia. Este último abundó más en el tema al señalar que el problema se debía a la calidad del

\section{(이요 $\$$}


aire húmedo que afectaba a los granos, de manera que de los que se cogían en junio apenas se conservaban para su siembra en octubre. Arregui (1980) nos proporcionó, además, una radiografía del cultivo del trigo en aquel reino:

De todo lo cual se puede bien entender la calidad de la tierra, y ver la gran providencia pues a los de acá (Nueva Galicia), que no pueden sembrar más de una vez trigo al año, ni se puede guardar, les da para que se supla esta falta, disposición para sembrar dos veces maíz, y lo que les quita por el calor de lo uno, se lo da de lo otro, haciendo lo mismo con los de allá (Nueva España), que si por el frío les niega segunda sementera de maíz por él se las da de trigo... (p. 83).

Lo anterior no impidió que numerosas haciendas -entre las que destacan la de Cuisillos, Toluquilla, Mazatepec, Zapotepec, Los Cedros, Miraflores, Navajas, Santa Lucía, Copala, Huastla, Atequiza, Guascato, Santa Ana Atistac, Estipac y Tepechitlán-se dedicaran al cultivo intensivo del trigo.

El cultivo del trigo requería de mucho cuidado y una fuerte inversión en infraestructura. Era indispensable contar con una mínima dotación de bueyes para el arado con los aperos para las yuntas (coyundas, rejas, yugos, arados con sus puntas de fierro), las herramientas para las labores del campo como azadones, coas, hoces, casangas, machetes, palas, trinchetes, carretas, chiquihuites y hachas. También se necesitaban animales como mulas o caballos para la trilla y transporte del grano o harina a Guadalajara. Una hacienda debía tener dentro de sus instalaciones una o varias trojes en donde guardar el trigo en greña o limpio, sus espacios de tierra firme algunas veces empedrada o de cantera en donde se realizaba la trilla, casa principal y jacales en donde vivían los trabajadores, una carpintería, potrero para guardar el ganado y acequias (véase mapa 1 ).

Uno de los bienes más importantes y valiosos en una propiedad agrícola de este tipo era su molino. Cuando en 1618 Diego Porres Baranda compró la hacienda de Mazatepec, ubicada en la jurisdicción de Tlajomulco, pagó por ella la cantidad de 12000 pesos de oro común. Esta se componía de cuatro sitios de ganado mayor, una labor de trigo por riego que medía ocho caballerías de tierra en la que había sembradas 60 cargas de esa semilla, un molino y 400 becerros de herradero. Al momento de la compra, la finca se encontraba muy devaluada debido a que le faltaban los animales y los esclavos. Según el antiguo poseedor y varios testigos expertos en las labores del trigo y crianza de ganados, el valor de la hacienda cuando estaba bien aviada alcanzaba los 24000 pesos, pues tan sólo el molino valía los 12000 pesos en que se había

\section{(이이 $(3$}




\section{SECUENCIA}

Secuencia, ISSN 0186-0348, núm. 94, enero-abril de 2016, pp. 39-76

Mapa 1. Nueva Galicia y la zona triguera aquí estudiada

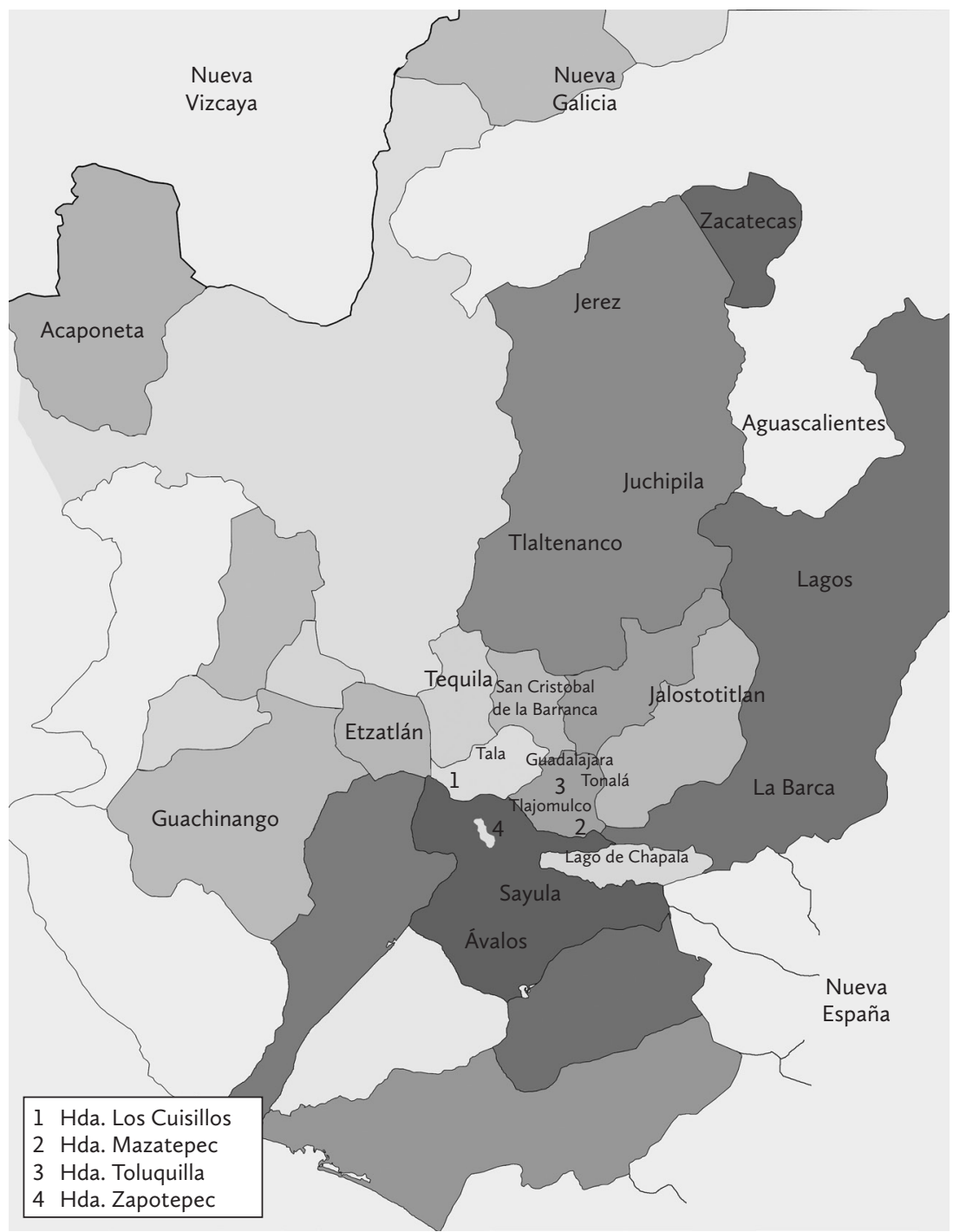

Fuente: elaboración propia a partir de Tanck (2005, p. 85).

\section{(ㄷ)(1) (8)}


comprado. ${ }^{7}$ Un año después, su propietario la había transformado en una "bien regada hacienda de trigo" donde producía harina que vendía en Guadalajara (Chevalier, 1999, p. 261).

Prácticamente todas las grandes haciendas tuvieron al menos un molino. La de Cuisillos que fue la más importante productora de harina durante el siglo XVII, contaba en 1629 con un molino y un granero bastante grande en donde cabían almacenadas 1500 fanegas de trigo. Su propietario destinaba 227 yuntas de bueyes para el arado de las tierras en donde sembraba este grano. Pero, además, poseía otros tres molinos en la ciudad de Guadalajara, sobre la vera del río San Juan de Dios. En ellos molía la mayor parte del grano que llegaba de su finca y ahí mismo vendía la harina. ${ }^{8}$

Los pequeños labradores que no contaban con los medios para instalar uno pagaban el costo de molienda y transporte aumentando con ello sus gastos de producción. En 1674 los agricultores del pueblo de Atotonilco El Bajo, en la jurisdicción de La Barca, pagaban un precio excesivamente alto por este servicio, pues al que acudían les cobraba seis reales por cada carga, cuando el precio corriente en otras partes de Nueva España era de tres reales para los indígenas y cuatro para los españoles. Además sufrían muchas mermas por las malas condiciones del mismo, que arrojaba mucho trigo por entre las piedras y este se perdía en el agua pues como no tenía presa, la corriente lo arrastraba por el río. ${ }^{9}$ Algunos otros productores de mediana capacidad económica optaban por rentar algún molino de una hacienda en decadencia o de alguna viuda imposibilitada de trabajarlo. Por ejemplo, en 1689 Pedro de Robles tomó en arrendamiento el de su cuñada viuda por el tiempo de cinco años pagándole 300 pesos de oro común anualmente. ${ }^{10}$

Otra inversión que demandaba este cultivo era la construcción y mantenimiento de acequias para conducir el agua que se necesitaba en abundancia para el riego de los sembradíos, pues como ya señalamos, en Nueva Galicia casi todo el trigo era de regadío. La utilización de este líquido en la industria triguera siempre contó con la protección de las autoridades al momento en

${ }^{7}$ Venta de Hacienda. 2 de noviembre de 1618. Notario Francisco Guerrero. Vol. único, f. 554f. Archivo de Instrumentos Públicos de Guadalajara (en adelante AIPG), México.

${ }^{8}$ Inventario de Hacienda. 6 de octubre de 1629. Francisco de Orendain. Vol. 1, fs. 255f-257v. AIPG, México.

${ }_{9}$ Queja de los indígenas de Atotonilco El Bajo. 3 de noviembre de 1674. Libros de Gobierno. Vol. 2, exp. 232, fs. 306f-307f. AIPG, México.

${ }_{10}$ Arrendamiento de Molino. 27 de octubre de 1689. José López Ramírez. Vol. 6, fs. 197f-198f. AIPG, México.

\section{(이요 $\$$}


que estas repartían las concesiones de la misma, a pesar de la oposición que presentaban algunos pueblos. El siguiente caso ilustra muy bien lo que aquí señalo. En 1675 el propietario de la hacienda de Los Cedros, el médico Simón de Oro, solicitó licencia ante la Audiencia para sacar agua de la laguna de Cajititlán y construir un canal con compuerta para regar sus sembradíos de trigo.

Los habitantes de los pueblos de Cajititlán, Tlajomulco, Cuyutlán y San Lucas, aledaños a esa laguna, se opusieron argumentando que la cantidad de agua que se sacaría era mucha y con ello se podría secar la laguna. El fiscal de la Audiencia respaldado en el hecho de que las cosechas de trigo eran muy escasas lo que ocasionaba que los precios del pan fueran muy altos en ese reino y sobre todo tomando en cuenta la poca comodidad que tenían los labradores de esa industria que requería de muchas inversiones en sacas de agua, sostuvo que era obligación de las autoridades alentarlos y darles los medios necesarios para sus sementeras; concluyó que se debía autorizar esa concesión, como así ocurrió. ${ }^{11}$

Algunos dueños con el afán de incrementar la producción o realizar mejoras en sus instalaciones recurrían a la iglesia para obtener dinero prestado hipotecando a través de censos sus propiedades. Un claro ejemplo de lo anterior fue Diego de Puga Villanueva. Él era poseedor del mayorazgo que había fundado su bisabuelo Andrés de Villanueva en los últimos años del siglo XVI en el valle de Atotonilco El Alto, en la jurisdicción de La Barca. ${ }^{12}$ Gracias a que su finca sólo tenía impuesto un censo de 500 pesos, y debido a que ella se encontraba muy deteriorada, solicitó un préstamo de 7000 pesos sobre su hacienda y su molino ubicado en Atotonilco El Alto. El dinero lo quería para aumentar el cultivo del trigo en dos parcelas que tenía para ello.

Argumentaba que aviándola y poniéndola al corriente, podría levantar una cosecha anual de 800 cargas ya que en ese tiempo sólo cogía 100 porque casi todas sus tierras las arrendaba a otros labradores. Calculaba que arreglando el molino, podría obtener unos 2000 pesos de renta al año pues en ese valle se cosechaban casi 3000 cargas de trigo y muchos cultivadores acudían a molerlo ahí, incluso de otras jurisdicciones. Después de todo el trámite logró conseguir el préstamo. ${ }^{13}$

${ }^{11}$ Licencia para sacar agua. 23 de febrero de 1675. Libros de Gobierno. Vol. 2, exp. 249, fs. 340f-349v. AIPG, México.

${ }^{12}$ Pleito por sucesión de mayorazgo. 1621. Manuscritos. Vol. 16, fs. 42-55. Biblioteca Pública del Estado de Jalisco (en adelante BPEJ), México.

${ }^{13}$ Imposición de censo. 05-05-1694. Real Audiencia de Guadalajara. Ramo civil. Exp. 11-8-149. вреј, México.

\section{(ㅇ)(1) $\$$}




\section{LA MANO DE OBRA}

Una característica del cultivo de trigo en Nueva Galicia durante el siglo XVII fue su gran dependencia hacia la mano de obra indígena a través de los repartimientos forzados asalariados, aunque también hubo trabajadores libres, peones acasillados y esclavos negros. Es importante resaltar en este trabajo el contraste que se da entre el sistema de repartimiento en este reino y el del Valle de México, sobre todo en las cantidades de trabajadores destinados a las labores agrícolas.

En el momento de mayor auge de este sistema en Nueva Galicia, el número anual de ellos superó apenas la cifra de los 1000 , mientras que en el centro de México eran asignados 2400 indios a la semana, distribuidos entre 114 agricultores españoles. Lo notable es que cada uno de ellos recibía un número de 20 indígenas. En cambio, en Nueva Galicia, las asignaciones a cada agricultor fueron mayores. Quizás la gran diferencia sea en que desde principios del siglo XVII se comenzó a manejar en Nueva España la posibilidad de extinguir este sistema, cosa que se hizo realidad en 1633 (Gibson, 1996, pp. 231-241). En contraparte, en el reino neogallego sólo a mediados del siglo XVII, cuando la población aborigen llegó a su punto más bajo, se planteó la idea de suprimir este servicio, pero nunca se llevó a cabo y permaneció vigente hasta muy entrado el siglo xviII.

La utilización de la mano de obra indígena forzada a cambio del pago de un jornal se estableció por una cédula real de 1549 (García, 2005, pp. 85 y 248; Gibson, 1996, p. 228). De esta manera se intentó suprimir el uso de los servicios personales establecidos en las tasaciones de tributos que se les hacían a los distintos pueblos de indios. Una posterior cédula redactada en 1550 otorgaba facultad al virrey para que pudiera disponer a su arbitrio de aquellos que no tuvieran algún oficio para que fueran alquilados en las labores del campo y en las obras de las ciudades (Zavala, 1987, t. 2, pp. 13-15). El virrey nombraba para ello a una persona de su confianza (que se conocía como juez proveedor o repartidor) para que señalara las cantidades que cada pueblo estaba obligado a mandar a las distintas labores agrícolas. En Nueva Galicia la reforma implementada en Nueva España no se aplicó sino hasta muchos años después, debido a la oposición que presentaron los encomenderos de aquel reino, logrando, con el aval de las autoridades locales, que la esclavitud de los indios en las minas y el sistema de servicios personales se mantuvieran vigentes (Zavala, 1987, t. 2, pp. 163, 204-207, 243 y 248-252).

\section{(ㅇ)(1) $(3$}


El sistema de repartimiento forzado asalariado en Nueva Galicia comenzó a funcionar en lugares con poca o nula presencia de encomenderos. La primera vez que se aplicó, los indígenas fueron destinados a la construcción de monasterios franciscanos en 1550 (Van Young, 1989, p. 249). Se fortaleció a partir de 1564, cuando la corona tomó la administración de las salinas e impuso la obligación a varios pueblos para que enviaran trabajadores a levantar la cosecha, pagándoles a cambio su salario y alimentación (Enciso, 1998, p. 201). En el sector agrícola, la asignación más antigua encontrada para Nueva Galicia data de 1592. En ese año, el virrey de la Nueva España ordenó al alcalde mayor de la provincia de Ávalos que proporcionara 72 indios al padre administrador de la hacienda de Toluquilla, para los cultivos de sus maíces y trigos. ${ }^{14}$

El procedimiento para enviar trabajadores indígenas iniciaba cuando los dueños de haciendas solicitaban al gobernador de Nueva Galicia trabajadores para sus labores agrícolas, pues él era el único facultado para hacer los repartimientos. En ausencia de este, la Audiencia, que asumía el papel de gobernadora, era la que los concedía. Después de aceptar la solicitud de un hacendado, el gobernador, que también era el presidente de la Audiencia, enviaba un escrito al alcalde mayor o al corregidor para que se encargaran de enviar las cantidades requeridas. Se comisionaba a una persona que recibía el cargo de juez repartidor de indios para que acudiera personalmente ante las autoridades de los distintos pueblos y los compeliera a enviar los trabajadores señalados.

Estas solicitudes se hacían dos veces al año. En la primera se pedía un número menor de indios para que realizaran los barbechos de las tierras, construyeran y limpiaran acequias y, sobre todo, para que sembraran el trigo. La temporada de este trabajo era entre septiembre y noviembre. En la segunda, la cantidad solicitada era mayor porque se requería realizar la siega y trilla del mismo. El tipo principal de trabajadores que se necesitaban era el de muchachos pajareros que se encargaban de espantar a los pájaros que picoteaban el trigo y el de adultos llamados segadores que eran los encargados de cortar las espigas. Una vez cortadas estas entraban en acción los alzadores y carreteros que las trasladaban a las eras donde era trillado y aventado para limpiarlo y separar los granos, quedando listo para su molienda. Este trabajo

${ }^{14}$ Repartimiento de mano de obra. 6 de noviembre de 1592. Indios. Vol. 6, exp. 256, f. 65f-v. Archivo General de la Nación (en adelante AGN), México.

\section{(ㅇ)(1) $\$$}


iniciaba en el mes de abril y concluía a fines de mayo o aun a principios de junio, justo antes de que llegaran las lluvias.

Los gobernadores de cada pueblo estaban obligados a obedecer la orden de enviar trabajadores, pues de no hacerlo eran multados con 100 pesos y a los indígenas que no acudían a laborar a la hacienda que les correspondía se les infraccionaba con diez pesos. Las condiciones que se imponían en los mandamientos eran que los trabajadores no fueran albañiles, carpinteros o de ningún oficio, también estaban exentos los gobernadores, principales y sus familiares. La jornada laboral era de sol a sol con dos horas de descanso, los indígenas debían trabajar exclusivamente para lo que señalaba el mandamiento y no podían ser destinados a otras labores. No trabajaban los domingos ni días festivos y se les debía de pagar en efectivo. El salario era de dos reales por día para los segadores, los que barbechaban y sembraban; a los muchachos pajareros se les pagaba un real. Se les debía de dar además la comida y su salario comenzaba a contar desde el momento en que salían de sus pueblos y terminaba cuando regresaban a ellos. Por concepto de viaje de ida y vuelta se les pagaba medio real por día y otro medio real por comida. ${ }^{15}$

Algunos pueblos, incluso, fueron forzados a llevar las herramientas de trabajo. Así les pasó a los de Tlajomulco, San Agustín, Santa Cruz, Santa Ana Tepetitlán, San Sebastián, Toluquilla y Analco, que aportaban carretas a la hacienda de Los Cuisillos. ${ }^{16}$ Los del pueblo de Jomulco, en la jurisdicción de Aguacatlán, tenían la obligación de llevar los bueyes y los aperos necesarios para la siembra ${ }^{17}$ De modo que además de la mano de obra, los propietarios se veían bastante beneficiados al ahorrarse el desgaste de herramientas y de animales. Todo esto justificado por la dependencia de Guadalajara de las cosechas de trigo, ${ }^{18}$ o como lo expresó el presidente de la Audiencia de aquella ciudad cuando se negó en 1671 a reducir el número de indios repartidos del pueblo de Tequila "pues de esto depende el sustento de esta ciudad y del reino"19 (véase cuadro 1).

\footnotetext{
${ }^{15}$ Repartimiento de mano de obra. 27 de abril de 1688. Libros de Gobierno. Vol. 1, f. 76fv. AIPG, México.

${ }^{16}$ Repartimiento de mano de obra. 30 de marzo de 1621. Libros de Gobierno. Vol. 356, f. 68v. AIPG, México.

${ }^{17}$ Repartimiento de mano de obra. 16 de junio de 1699. Libros de Gobierno. Vol. 15, f. 121f-v. AIPG, México.

${ }_{18}$ Repartimiento de mano de obra. 27 de marzo de 1688. Libros de Gobierno. Vol. 23, f. 55f-v. AIPG, México.

19 Repartimiento de mano de obra. 2 de mayo de1671. Libros de Gobierno. Vol. 1, exp. 109, f. 75f-v. AIPG, México.
}

\section{(이요 $\circledast$}


Cuadro 1. Repartimiento por año de indios en Nueva Galicia por jurisdicción, siglo XVII

Jurisdicción $\begin{array}{lll}1620 & 1621 & 162\end{array}$ 1623

$\begin{array}{lll}1657 & 1658 & 1659\end{array}$

16601661

\begin{tabular}{|c|c|c|c|c|c|c|c|c|c|}
\hline Acaponeta & & & 1 & & & & & & \\
\hline Aguacatlán & 1 & & 30 & & & & & & \\
\hline Chimaltitán & & 10 & & & & & & & \\
\hline \multicolumn{10}{|l|}{ Cocula } \\
\hline \multicolumn{10}{|l|}{ Colimilla y } \\
\hline \multicolumn{10}{|l|}{ Etzatlán } \\
\hline Guachinango & & 11 & & & & & & & \\
\hline Guadalajara & 85 & 382 & 261 & & & 180 & 180 & 36 & 99 \\
\hline Hostotipaquillo & 6 & & & & & & & & \\
\hline Jerez & & 30 & & & & & & & \\
\hline Juchipila & 32 & 80 & 80 & & 140 & & 71 & 170 & 120 \\
\hline La Barca & 50 & 116 & & & 66 & 58 & 52 & 24 & 82 \\
\hline Lagos & & 6 & 5 & & & & & & \\
\hline No Identificado & 46 & 202 & & & & & & & 50 \\
\hline Ostotipac & 30 & 12 & & & & & & & \\
\hline Peñol Blanco & & 150 & 300 & & & & & & \\
\hline Santa María & & & & 150 & & & & & \\
\hline Sierra P. & 6 & & & & & & & & \\
\hline San Cristóbal & 21 & & & & 50 & & & & 12 \\
\hline Tala & 464 & 537 & 582 & & 110 & 136 & 46 & 45 & 185 \\
\hline Tequila & 22 & 72 & 50 & & & 20 & 14 & & \\
\hline Tlajomulco & 70 & 179 & 88 & & & 104 & 15 & 47 & 406 \\
\hline Tlaltenango & & & & & 100 & & & & 100 \\
\hline \multicolumn{10}{|l|}{ Zacatecas } \\
\hline Total & 841 & 1787 & 1397 & 150 & 466 & 498 & 378 & 322 & 1054 \\
\hline
\end{tabular}

\section{(이요 $(3$}


Jurisdicción 1662

$\begin{array}{lllllll}1668 & 1670 & 1671 & 1672 & 1673 & 1674 & 1675\end{array}$

Acaponeta

Aguacatlán

Chimaltitán

Cocula

Colimilla y

Matatán

20

Etzatlán

Guachinango

Guadalajara

224

160

226

186

186

186

186

Hostotipaquillo

Jerez

Juchipila

$120 \quad 70$

La Barca

$96 \quad 40$

132

Lagos

$30 \quad 30$

No Identificado

$64 \quad 24$

Ostotipac

Peñol Blanco

Santa María

Sierra P.

San Cristóbal

$36 \quad 45$

20

20

20

20

Tala

$115 \quad 180$

220

220

220

$180 \quad 240$

255

Tequila

Tlajomulco

399

544

392

460

406

$336 \quad 340$

Tlaltenango

100

NI

Zacatecas

Total

$1154 \quad 1063$

22

$1020 \quad 1043$

919

945

944

\section{(이요 $(3$}


Jurisdicción $1676 \quad 1677 \quad 1678$

Acaponeta 40

Aguacatlán

Chimaltitán

Cocula

Colimilla y

Matatán

70

$120 \quad 120$

Etzatlán

70

Guachinango

Guadalajara

180

186

180

180

50

212

Hostotipaquillo

Jerez

Juchipila

La Barca

59

246

127

127

92

127

127

127

Lagos 42

No Identificado

Ostotipac

Peñol Blanco

NI

Santa María NI

Sierra P.

San Cristóbal

$20 \quad 64$

64

Tala

250

180

30

Tequila

Tlajomulco

351

180

180

180

180

$180 \quad 180$

Tlaltenango

150

480

578

726

469

606

Zacatecas

Total

\section{(이요 $(3$}


Jurisdicción 168

686

1687

1688

1689

1690

1691

1692

1693

Acaponeta

Aguacatlán 70

Chimaltitán

NI

Cocula

12

Colimilla y

Matatán

144

96

$124 \quad 95$

Etzatlán

60

57

57

$50 \quad$ NI

58

Guachinango

20

Guadalajara

180

Hostotipaquillo

Jerez

12

Juchipila

$\begin{array}{rrrrrrrr}98 & 173 & 183 & 128 & 117 & 193 & 281 & 152 \\ & & & & & 50 & & \end{array}$

Lagos

No Identificado

Ostotipac

Peñol Blanco

Santa María

Sierra P.

San Cristóbal

$20 \quad 24$

20

Tala

$180 \quad 180$

180

186

180

$180 \quad 180$

360

Tequila

Tlajomulco

424

398

514

456

222

410

332

380

Tlaltenango

16

Zacatecas

45

Total

$996 \quad 1116 \quad 1064 \quad 940$

339

903

$809 \quad 1147$

\section{(이요 $(3$}


Jurisdicción 169 1695

Total

Acaponeta

Aguacatlán

Chimaltitán

Cocula

Colimilla y

Matatán

Etzatlán

Guachinango

Guadalajara

230

70

30

Hostotipaquillo

Jerez 12

76 873

50 402

Juchipila

60

1140

La Barca

191

66 66 163

Lagos 386

No Identificado 42

Ostotipac 450

Peñol Blanco 150

Santa María 6

Sierra P. 516

San Cristóbal 44 6871

Tala 180 178

Tequila

Tlajomulco 295

273

322

246
20

221

279 $611 \quad 12691$

Tlaltenango

Zacatecas

Total 487

$\mathrm{NI}=$ no identificado.

Fuente: AIPG,Libros de Gobierno.

\section{()(1) $(3$}


El análisis que aquí se hace sobre la relevancia de la mano de obra indígena de repartimiento en el cultivo del trigo está respaldado en 540 concesiones que se otorgaron específicamente para ese fin a distintos agricultores a lo largo del siglo XVII. Todas las haciendas que recibieron este beneficio se ubicaban en un radio no mayor de 90 kilómetros de Guadalajara; las más cercanas a esa ciudad como las de Cuisillos, Toluquilla, Zapotepec y Mazatepec fueron las que más indios recibieron. A algunas otras, que no estaban dentro de Nueva Galicia, también se les otorgó este tipo de mano de obra, como en Etzatlán, que pertenecía a Nueva España, o Cocula, que era de la Provincia de Ávalos. ${ }^{20}$

Una característica a resaltar del repartimiento de mano de obra para el cultivo del trigo es que el número de trabajadores asignados a las más grandes propiedades no variaba año con año. La hacienda de Los Cuisillos, por ejemplo, que se encontraba a unos 60 kilómetros al norponiente de Guadalajara, recibió durante la primera mitad del siglo XVII un promedio anual de 500 indígenas, aunque para la segunda mitad el número se redujo a 225: 180 acudían a la siega y trilla y 45 a barbechar y sembrar. Esta considerable baja se debió a la grave disminución de la población india en Nueva Galicia, que llegó a su punto más bajo en 1646.

Los indígenas que llegaban a Cuisillos procedían al menos durante la segunda mitad del siglo XVII de las jurisdicciones vecinas a ella como Tlajomulco, Tala y Tequila. Sólo durante la primera mitad del siglo, cuando el número de trabajadores era mucho mayor, llegaban desde lugares más alejados, como Juchipila, Jerez, Tlaltenango, Mesquituta, Moyagua, Nochistlán, Guachinango y Aguacatlán. Ninguna otra hacienda recibió indios de lugares tan alejados. El hecho de contar con un abastecimiento seguro de mano de obra para el cultivo del trigo, más la población laboral fija para sus otras labores ganaderas y agrícolas, le permitió consolidarse como la principal productora y abastecedora de harina a Guadalajara a lo largo del siglo xviI.

La hacienda de Toluquilla, que pertenecía al colegio de la Compañía de Jesús de Guadalajara, fue la que recibió la segunda mayor cantidad de indios a lo largo del siglo XVII. Los jesuitas contaron, desde que adquirieron esta propiedad en 1587, con una serie de privilegios que les permitió desarrollar en las puertas de Guadalajara uno de los complejos agroganaderos más im-

${ }^{20}$ El peso de aportar trabajadores de repartimiento recayó en más de 60 pueblos. Entre los que más indios enviaron fueron los de Cajititlán, Cuyutlán, Tlajomulco, Tonalá, Tequila, Toluquilla, Tala, San Agustín, Nestipac, Tesistán, Poncitlán, Mesquituta, Moyahua, Tlaltenango, Teul, Apozol, Jalpa, Mecatabasco, etcétera.

\section{(ㅇ)(1) 3}


portantes de aquel reino. Nunca tuvo las grandes extensiones de tierra como la de Cuisillos u otras circunvecinas. Apenas contaba con un sitio de ganado mayor, uno de menor y ocho caballerías de tierra. En estas últimas desarrolló una agricultura intensiva de trigo y maíz basada en el sistema de riego y la utilización de una gran cantidad de bueyes para arar. Esta finca, al igual que la de Cuisillos, contaba con su fuerza laboral fija compuesta por esclavos negros e indios asalariados libres. Pero, a diferencia de aquella, contó con el beneficio de recibir dobles asignaciones por parte de las audiencias de México y Guadalajara. De esta última recibía un promedio anual de 180 indígenas.

La tercer hacienda que más indios recibió fue la de Los Cedros, que se localizaba en la jurisdicción de La Barca, con un promedio de 127 trabajadores por año, divididos en 35 para la siembra y 92 para la cosecha del trigo. Estoy seguro que los que acudían a laborar en ella eran más, pues al igual que la de Toluquilla se beneficiaba de repartimientos otorgados por la Audiencia de México. Al menos así lo demuestran varias relaciones de gastos de la hacienda por algunos años, en los que se asientan los salarios pagados a 33 personas del pueblo de Jocotepec que habían sido mandados por órdenes del virrey. ${ }^{21}$ Pero estos indígenas no aparecen registrados en los libros de gobierno de la Audiencia de Guadalajara porque ella no era quien los asignaba.

Mención aparte merece un grupo de cuatro propiedades ubicadas en dos de los valles más fértiles de ese reino, en la jurisdicción de Tlajomulco, el de Mazatepec y el de Zapotepec. En su conjunto, estas concentraron la mayor cantidad de repartimientos en todo el siglo. De hecho, juntas representan $38 \%$ del total de asignaciones que tenemos registradas para esa centuria. Las analizo en conjunto porque pertenecieron durante más de 100 años a una misma familia. Cuatro hermanos eran los propietarios de ellas y posteriormente los hijos de cada uno de ellos las continuaron administrando hasta mediados del siglo XVIII. Por la continuidad de los repartimientos de indios a ellas, se deduce que fueron las mejor protegidas por parte de las autoridades debido a su cercanía con Guadalajara y como una forma de asegurar el abasto de trigo o harina a ella. Al menos desde 1671 y hasta los primeros años del siglo XVIII no hubo una sola ocasión en que se quedaran sin trabajadores para las labores del trigo. A cada uno se le entregaba anualmente un promedio de 85 hombres, divididos en las temporadas de siembra y cosecha (véase cuadro 2).

${ }^{21}$ Avalúo e inventario de hacienda. 10 de noviembre de 1659. Sección Gobierno. Serie Haciendas. Caja 1, exp. fechado 1659-11-10. Archivo Histórico del Arzobispado de Guadalajara (en adelante AHAG), México.

\section{(ㅇ)(1) $\$$}




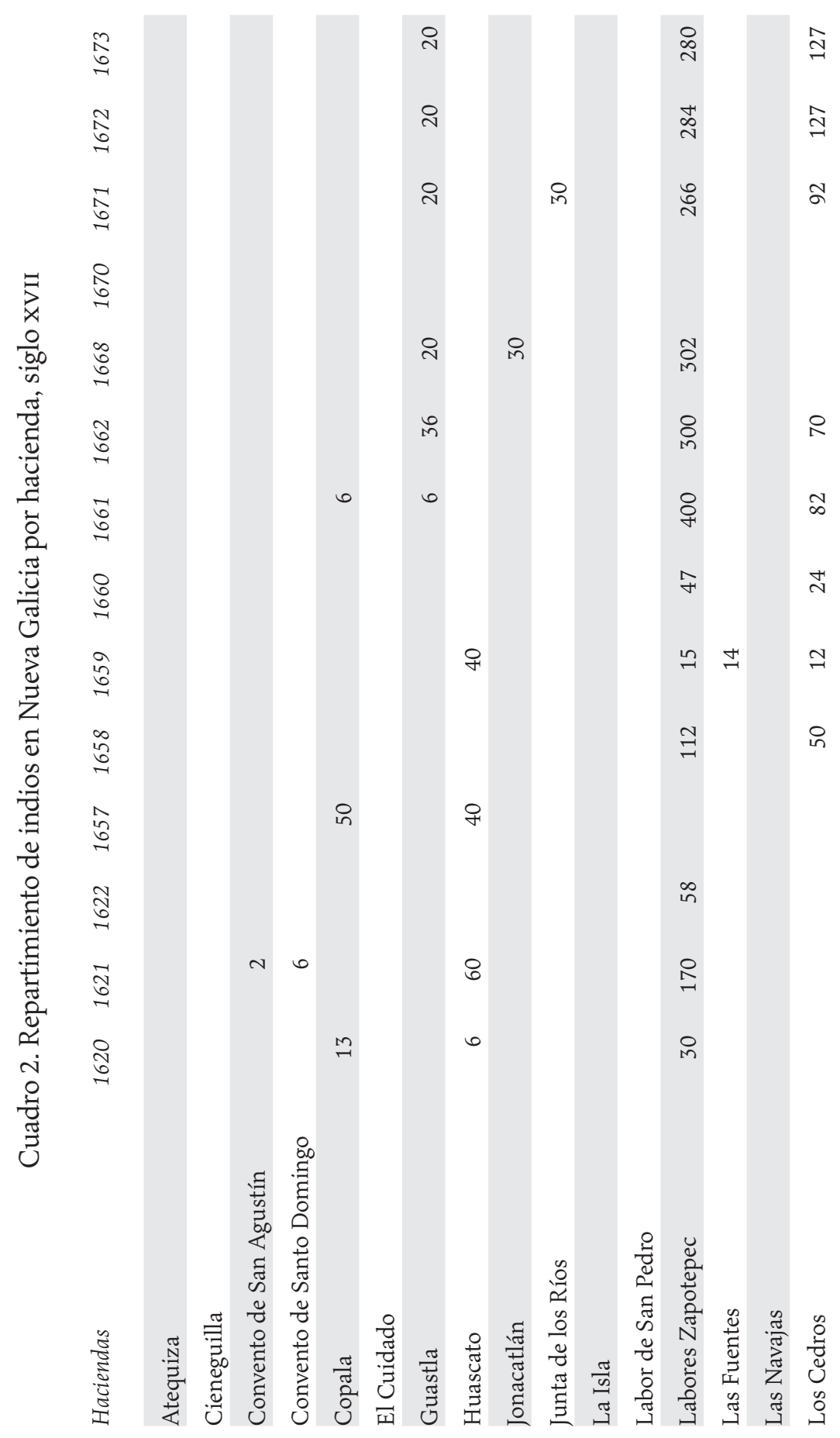

\section{(이)(1)}




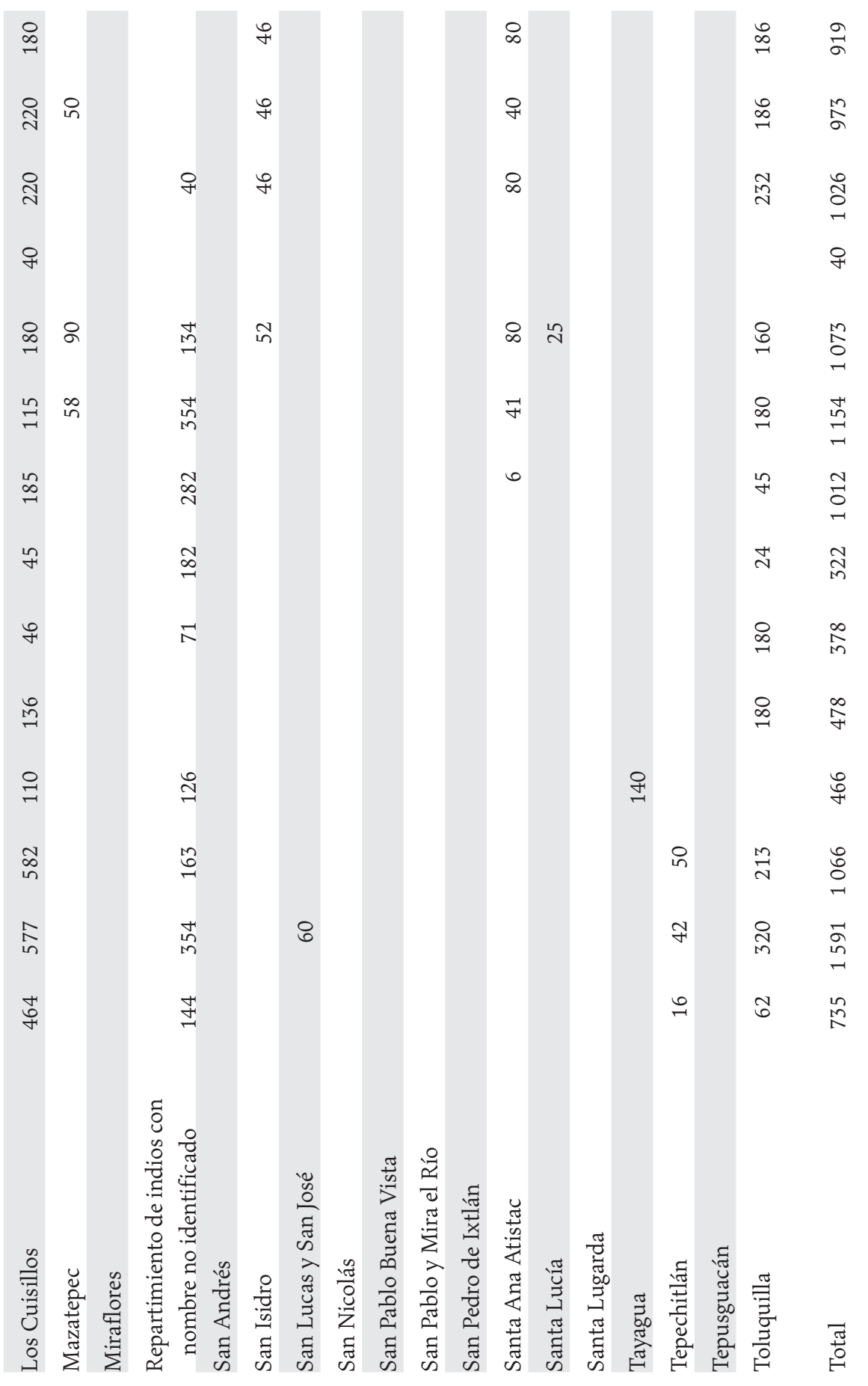

\section{(ㄷ)(1)(8)}




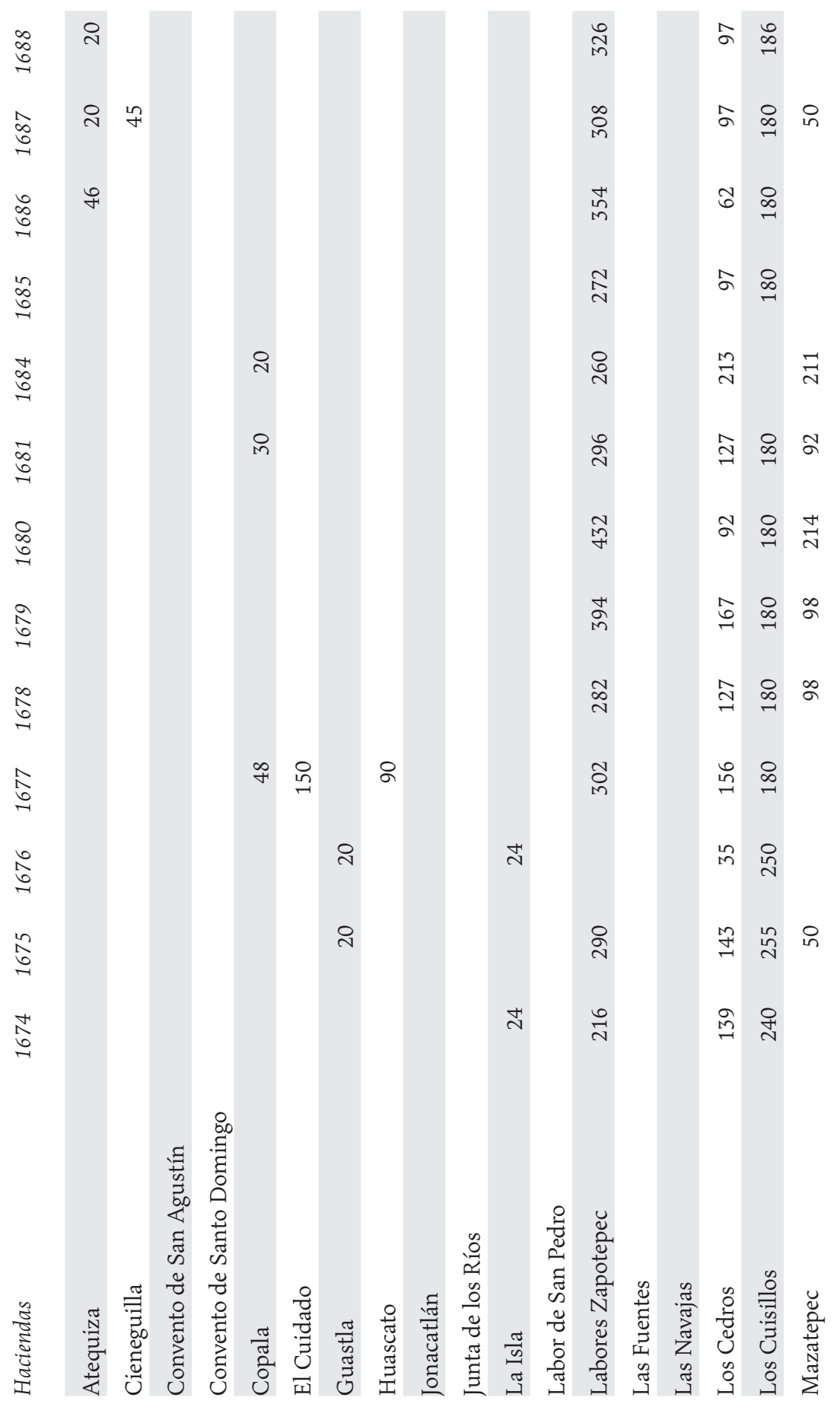

\section{(ㄷ)(1) (8)}




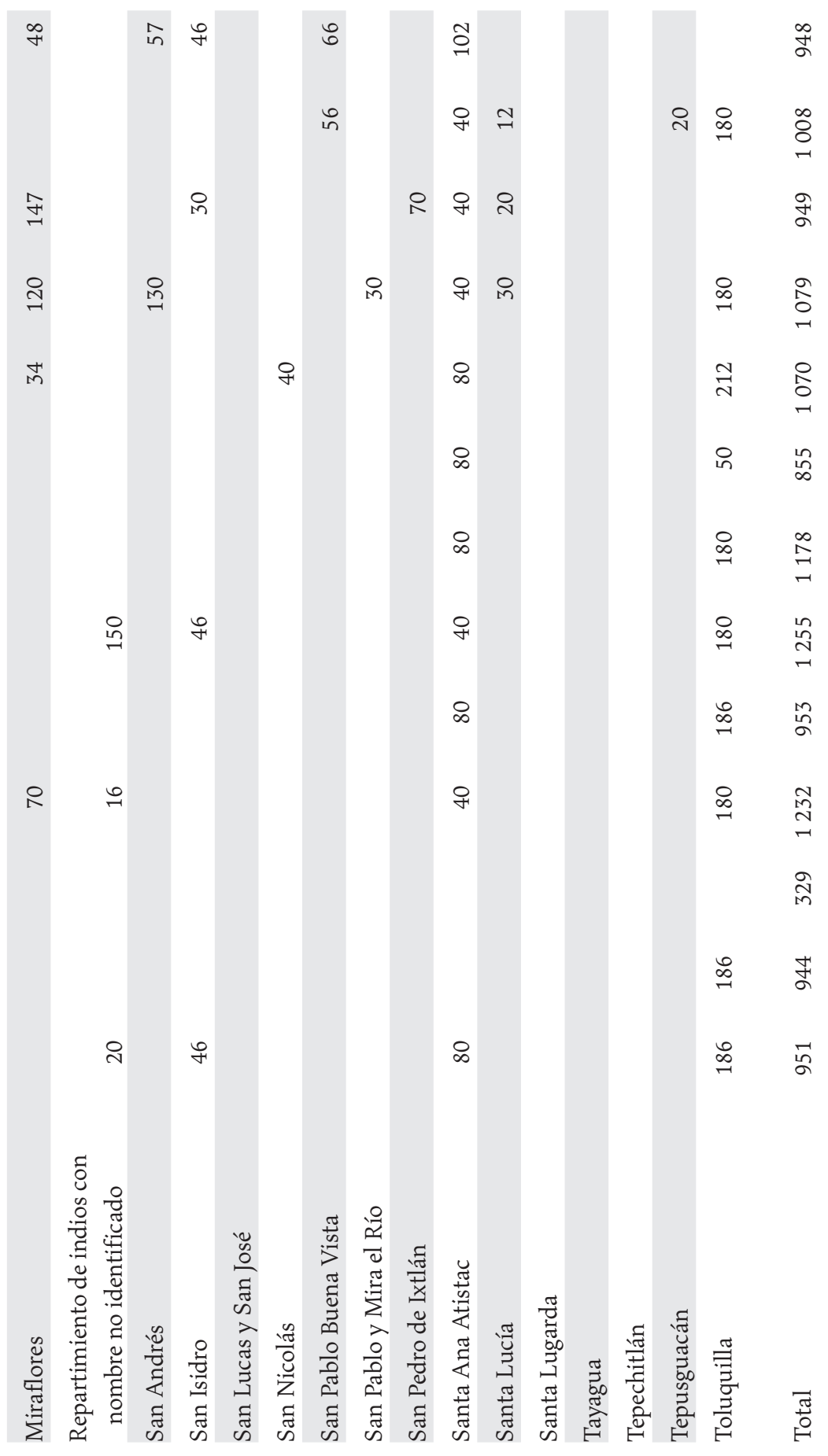

\section{(ㄷ)(1)(8)}




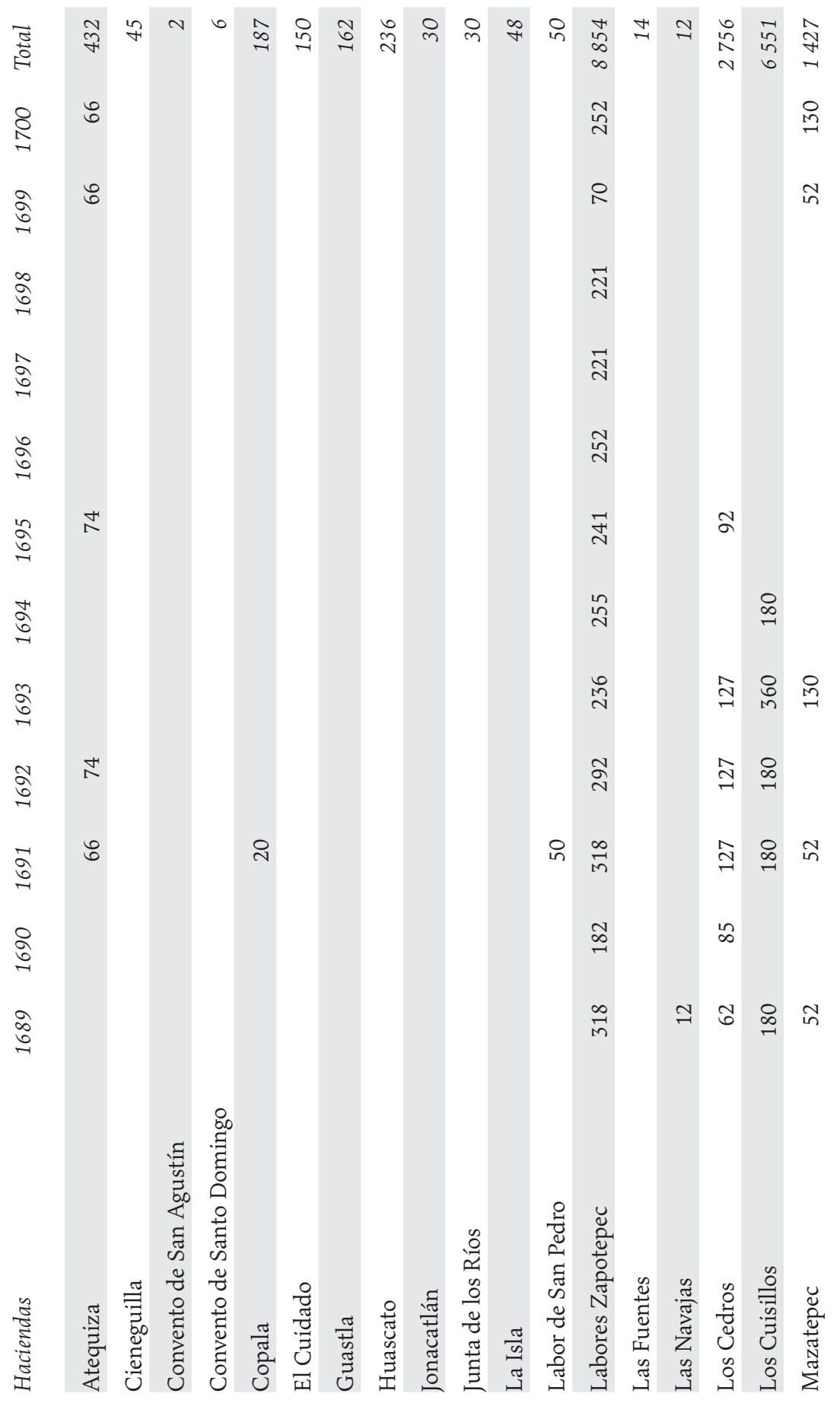

\section{(ㄷ)(1) (8)}




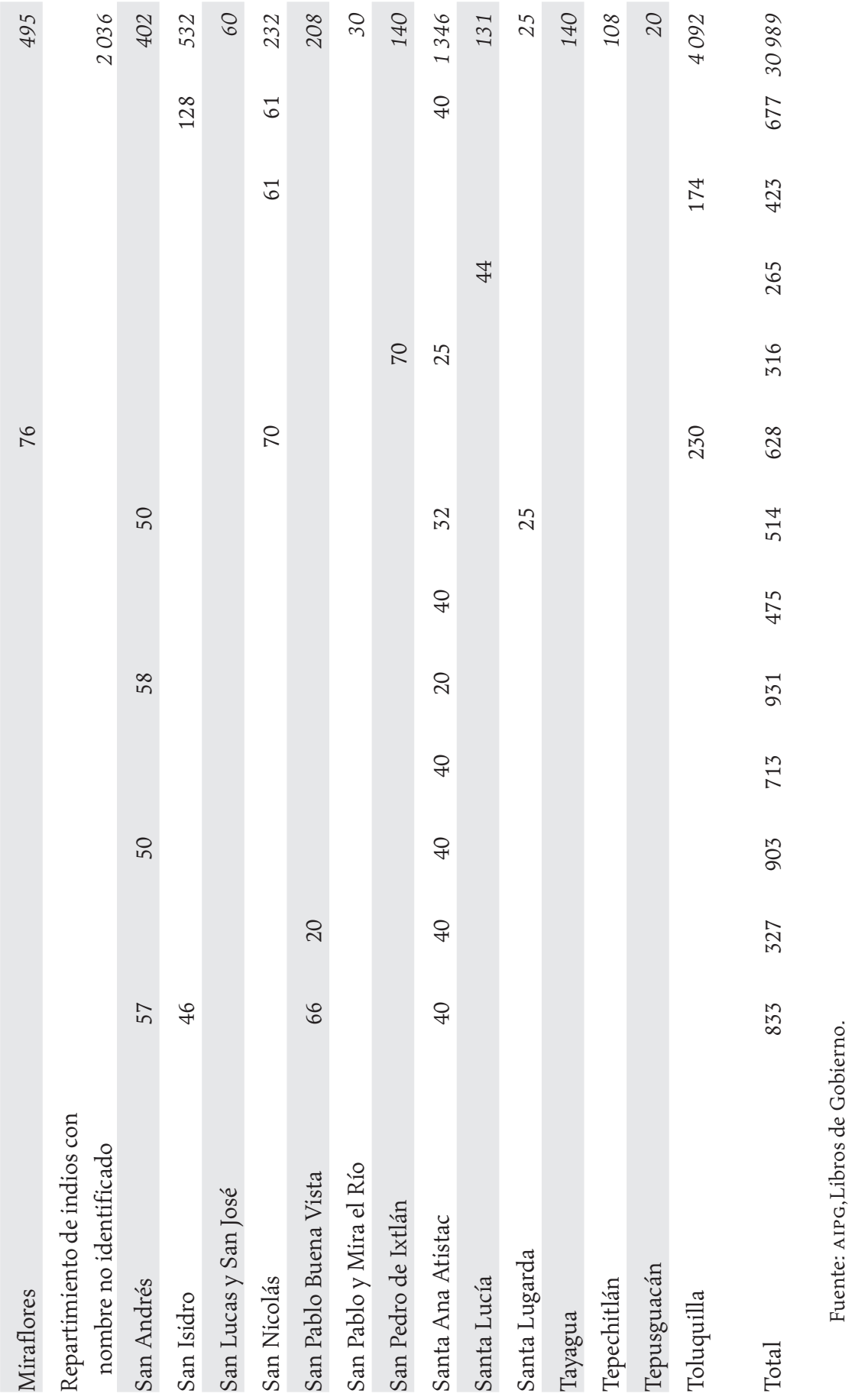

\section{(ㄷ)(1) (8)}


El número de propietarios que se beneficiaron al recibir mano de obra indígena de repartimiento para el cultivo del trigo fue bastante numeroso. Los que se encontraban dentro de la jurisdicción de la ciudad de Guadalajara, sin contar a la hacienda de Toluquilla, representan 13\% del total de asignaciones de indios para trabajar en el cultivo del trigo que tengo registradas. El resto se distribuye en otras jurisdicciones localizadas, como lo señalé al principio, en un radio no mayor de 90 kilómetros de la capital neogallega (véase gráfica 1).

No siempre las autoridades indígenas respondieron satisfactoriamente a la orden de enviar trabajadores a las haciendas; muchas veces se opusieron a pesar de las fuertes multas que se les imponían. Su principal argumento era que se les pedía un número bastante alto no sólo para las labores agrícolas, sino para otros trabajos de obras públicas que necesitaba la ciudad de Guadalajara lo que provocaba el abandono de sus sementeras. Alegaban en su favor que muchas de las veces no recibían los salarios estipulados, pero, sobre todo, resaltaban el hecho de que no tenían el suficiente número de pobladores para cumplir con la cuota que se les imponía año tras año.

El problema de la disminución de los indios no era sólo un pretexto que ellos utilizaban para evadir el sistema de trabajo, era una realidad. Desde el año de 1646 el presidente de la Audiencia de Guadalajara Pedro Fernández de Baeza había informado al rey que debido a las graves daños que recibían los indígenas en las labores de las minas y en los repartimientos, estos estaban a punto de extinguirse pues en los 148 pueblos que había en el reino de la Nueva Galicia apenas quedaban 1640 tributarios, y le solicitaba, entre otras cosas, la desaparición de los repartimientos de indios. ${ }^{22}$

Ante esta negativa frecuente de parte de los indios a acudir a trabajar al cultivo del trigo, los hacendados reaccionaron de distintas maneras. Algunos solicitaban a la Audiencia que exhortara o, aun, que metiera a la cárcel a los gobernadores que habían evadido el mandamiento de enviar indios a esas labores. O como el caso del colegio de la Compañía de Jesús de Guadalajara que solicitó, en 1671, que se acudiera a contar a los indios de los pueblos de Toluquilla y San Pedro, pues las autoridades de esos lugares, con el pretexto de no contar con los indios suficientes, se negaban a enviar trabajadores a su hacienda. ${ }^{23}$

${ }^{22}$ Informe del presidente de la Audiencia de Guadalajara. 30 de diciembre de 1646. Cédulas Reales Originales. Vol. 2, exp. 129, fs. 274f-275v. AGN, México.

${ }^{23}$ Repartimiento de mano de obra. 26 de abril de 1688. Libros de Gobierno. Vol. 1, exp. 110, fs. 75v-76f. AIPG, México. 


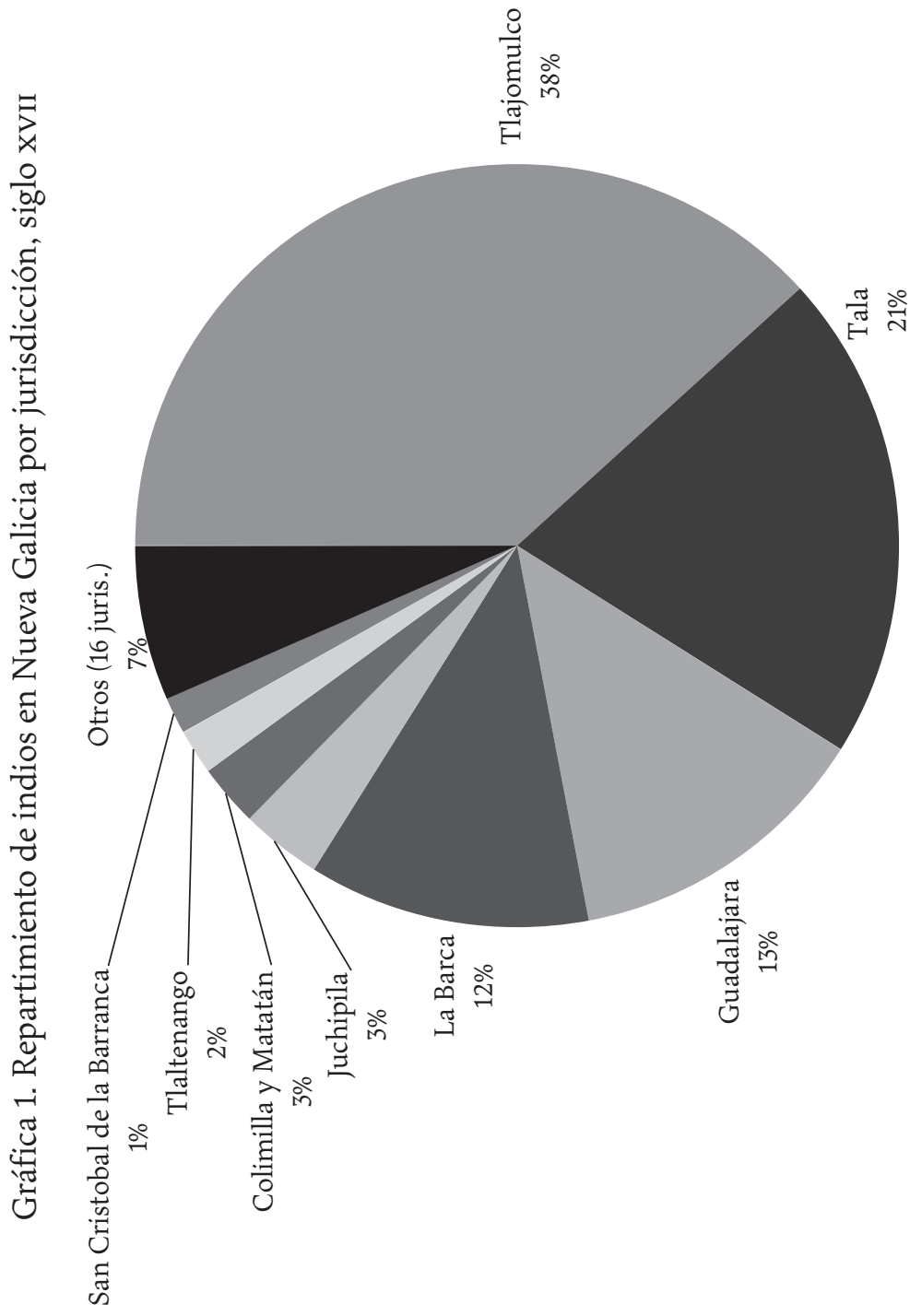

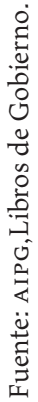

\section{(ㄷ)(1) $\$$}


Algunos otros hacendados reconocían que era evidente la falta de indios debido a que estos se estaban muriendo, aunque no por ello cesaron en su deseo de obtener trabajadores de repartimiento. En 1688, por ejemplo, el dueño de la hacienda de San Andrés, ubicada en Etzatlán, señalaba que desde años atrás él y los anteriores dueños continuamente presentaban pérdidas en parte de sus cosechas debido a la abundancia de las mismas y a que no tenían la gente suficiente para que las levantaran. Argumentaba que de recibir trabajadores el beneficio sería mutuo, pues sus frutos se venderían en Guadalajara y de esta forma la ciudad no carecería de ese cereal. Así logró que se le asignaran 57 indios. ${ }^{24}$ Un año después vemos al arrendatario de las tierras del mayorazgo de Porres Baranda -que se encontraba en el valle de Mazatepec, en la jurisdicción de Tlajomulco- solicitar que nuevos pueblos le fueran asignados para laborar en sus cosechas, pues en los que tenía señalados para su hacienda "no hay número suficiente por haberse consumido los más y algunos pueblos consumidose en el todo". En este caso nuevos pueblos fueron obligados a mandar 46 indígenas para que realizaran la cosecha del trigo en aquella propiedad. ${ }^{25}$ Ante la necesidad constante de trabajadores, hubo algunos hacendados que ofrecieron depositar por adelantado el salario de los trabajadores con tal de asegurar la mano de obra. ${ }^{26}$

La disminución de los indígenas en Nueva Galicia desde mediados del siglo XVII ocasionó que el círculo de las haciendas beneficiadas con el repartimiento de mano de obra se fuera cerrando, hasta quedar sólo aquellas que se encontraban en un radio no mayor de 70 kilómetros en torno a la ciudad de Guadalajara. Siguió presente la idea de que este sistema representaba un bien público. Tanto las autoridades como los agricultores lo consideraban la única solución pues señalaban que "no había otra forma de desarrollar la agricultura"; por eso, "se tenía mucho cuidado de dar gente de repartimiento a las labores, pues siempre se teme la falta de pan y maíz" (Arregui, 1980, p. 117). De ahí que este formato de asignación de trabajadores indios se mantuviera vigente hasta el primer tercio del siglo xviII.

Junto al sistema de repartimiento de mano de obra para el cultivo del trigo existió también el formato de mano de obra libre asalariada. Las rela-

${ }^{24}$ Repartimiento de mano de obra. 23 de abril de 1688. Libros de Gobierno. Vol. 23, fs. 73v-74v. AIPG, México.

${ }^{25}$ Repartimiento de mano de obra. 10 de noviembre de 1659. Libros de Gobierno. Vol. 70, f. 35v. AIPG, México.

${ }^{26}$ Repartimiento de mano de obra. 6 de mayo de 1689. Libros de Gobierno. Vol. 70, f. 130v. AIPG, México.

\section{(이요 $\$$}


ciones geográficas que se escribieron en 1579 detallan cómo los habitantes de los pueblos de Ameca y Tenamaztlán usualmente iban por su voluntad a contratarse por días o semanas a las haciendas agrícolas y ganaderas que existían en el valle de Ameca. El salario que obtenían (cuatro reales por seis días) les permitía en dos semanas juntar para el pago de su tributo que era de un peso al año. Cuando sus necesidades aumentaban las solucionaban regresando a trabajar (Acuña, 1988, pp. 47 y 291). Las visitas de los oidores de Nueva Galicia durante los primeros 20 años del siglo XVII confirman la costumbre existente en varios pueblos de que sus habitantes acudieran a alquilarse por su voluntad (Berthe, Calvo y Jimenez, 2000). Podríamos ubicar entonces el origen de esta relación laboral en la oferta atractiva ofrecida por las haciendas necesitadas de mano de obra, consistente en un trabajo estacional libre y bien pagado que permitía a los indígenas continuar con sus cultivos y aprovechar el tiempo de la llegada de sus cosechas en arrendar su mano de obra.

Gracias a unas relaciones de gastos de la hacienda de Los Cedros se puede ver la forma de pago por el trabajo realizado. En 1659, por ejemplo, los administradores de dicha propiedad, ubicada en la jurisdicción de La Barca, contrataron a 23 indios de Cajititlán por el tiempo de doce días para que levantaran la cosecha del trigo. A cada uno se le pagó en una sola exhibición dos pesos y medio que equivalía a 1-4-0 por día. El jornal de diez muchachos pajareros fue de un real y como también trabajaron doce días, recibieron 1-4-0 pesos. Otros diez segadores del pueblo de Jocotepec trabajaron seis días y se les pagó a dos reales el jornal. El mismo salario de dos reales por día recibieron cuatro indios que eran los encargados de transportar las carretas con el trigo a Guadalajara. ${ }^{27}$

\section{EL ABASTO DE TRIGO Y HARINA A GUADALAJARA}

Hacia 1570 Guadalajara era una ciudad pequeña con un reducido número de habitantes, vivían en ella unos 60 o 70 españoles que junto con sus esposas, hijos, esclavos y criados sumaban apenas 400 o 500 personas. En su entorno el número de indios rondaba entre 2500 y $3000 .{ }^{28}$ En los años siguientes, la

${ }^{27}$ Avalúo de hacienda, gastos de mano de obra. 10 de noviembre de 1659. Sección Gobierno. Serie Haciendas. Año de 1659. AHAG, México.

${ }^{28}$ Estos informes fueron escritos por el Cabildo Eclesiástico de Guadalajara y por fray Alonso de Pareja, guardián del convento franciscano de esa ciudad en 1570.

\section{(이요 $(2$}


cantidad se fue incrementando y ya en 1586 había entre 80 y 100 vecinos españoles. Para 1602 aumentaron a 160 con un aproximado de entre 1400 y 1800 habitantes (Borah, 1994, p. 36). Tres años después, el obispo Alonso de la Mota y Escobar señalaba que en la ciudad vivían 173 vecinos que con sus mujeres, hijos y personal de hábito llegaban a 500 españoles, más otro tanto en esclavos negros y mulatos, sin contar a otros de estas razas de condición libre (Mota, 1993, p. 25). Al iniciar la década de los veinte de aquel siglo ya había en esa ciudad 200 españoles (Arregui, 1980, p. 115) y para 1675 su número llegaba a 500. ${ }^{29}$

En los primeros años del siglo xvir la ciudad estaba bien abastecida de pescados y mariscos que llegaban desde las lagunas de Chapala y Cajititlán, del río Grande y del litoral del Pacífico. Las frutas, legumbres, leña y madera abundaban debido a que los indios de los pueblos periféricos las llevaban a vender -junto con artículos que fabricaban- en el mercado que se instalaba cada cinco días en la plaza principal. Los granos y animales provenían de las numerosas haciendas que se encontraban en los fértiles valles de Ameca, Tala, Tlajomulco, La Barca, Cocula, Zapopan, Tonalá y Toluquilla. Un alto porcentaje del trigo llegaba a la ciudad ya transformado en harina pues las principales haciendas contaban con su propio molino (Mota, 1993, p. 35). En Guadalajara había cuatro molinos ubicados sobre la margen del río San Juan de Dios. Cada uno contaba con dos piedras que eran movidas por agua y cada piedra molía 20 fanegas por día (López, 1971, p. 136; Mota, 1993, p. 26).

Hasta ahora no tengo pruebas suficientes que me permitan determinar si las cosechas de trigo y la producción de harina eran suficientes para cubrir las necesidades de consumo de los habitantes de Guadalajara. Los datos con que cuento son muy dispersos y se limitan al primer tercio del siglo XVII. Se sabe que en 1605 tan sólo en el valle de Tala había cinco o seis fértiles labores de trigo y en una de ellas se cosechaban 4000 fanegas (Mota, 1993, p. 35). Lázaro de Arregui, comerciante de Guadalajara, escribió en 1621 que en la jurisdicción de Tlajomulco había cuatro labores de trigo en las que se cosechaban de 4000 a 5000 fanegas. Agregaba que la producción de la hacienda de Cuisillos era de entre 7000 y 8000 fanegas de trigo (Arregui, 1980, pp. 121-122). Tres años después, cuando Juan González de Apodaca Rubín, dueño de la misma, tuvo que hacer un inventario de sus bienes, afirmó que sus tierras producían 17000 fanegas de trigo (Peña, 1983, p. 38). No hay manera de conocer las cantidades de trigo o harina que ingresaban anualmente

29 Informe sobre el número de habitantes en el reino de la Nueva Galicia. 1675. Guadalajara 13 R1 N. 8. Archivo General de Indias (AGI), Sevilla.

\section{(ㅇ)(1) $\$$}


a Guadalajara debido a que la mayor parte del siglo xvir no existió una alhóndiga, y cuando esta se estableció en 1672 funcionó a través de arrendarla a particulares. Tampoco es factible conocer o calcular la producción de las haciendas porque no hay registros de ello. Se pudiera pensar en recurrir a los libros de recaudación del diezmo pero estos tampoco existen ya que durante esa centuria el derecho a cobrarlo se arrendaba también a particulares.

¿Cómo explicar entonces el funcionamiento del abasto de trigo y harina a la ciudad de Guadalajara?, ¿cómo determinar si sus habitantes sufrieron o no de escasez? Intentaré esbozar una respuesta a partir de analizar las actuaciones de las autoridades tanto de la Audiencia como del Cabildo a partir del supuesto de una necesidad constante de estos productos alimenticios a lo largo de todo el siglo XVII. Vimos ya cómo la Audiencia privilegió a los agricultores que sembraban trigo, asegurándoles mano de obra de repartimiento. Cuando había tiempo de escasez, como el trienio de 1620-1622, este organismo amplió el radio de beneficiarios a lugares tan alejados como Tlaltenango, Jerez y Juchipila, con la condición expresa de que tenían que meter a la ciudad 100 quintales de harina cada uno. ${ }^{30}$

En su afán por conseguir suficiente trigo para cubrir las necesidades de los habitantes españoles en Nueva Galicia, las autoridades de la Audiencia de ese reino establecieron la prerrogativa de que los pueblos de indios que sembraran esta sémola quedarían exentos de los repartimientos agrícolas. Conozco al menos el caso de los indígenas del pueblo de Atotonilco el Alto, en la jurisdicción de La Barca, que adoptaron con entusiasmo este cultivo pues no sólo quedaron libres de mandar trabajadores, sino que aprovecharon el tener un mercado consumidor seguro para su producción ante la demanda constante de este cereal. Durante el último tercio del siglo xvir levantaban cosechas anuales de 800 cargas de trigo que, vendían en Guadalajara ya transformado en harina. ${ }^{31}$

La función desempeñada por los miembros del Ayuntamiento fue muy contrario a los del otro organismo a pesar de que en apariencia se preocupaban por resolver el problema de abastecimiento a la ciudad, vigilando que los labradores llevaran la cantidad de trigo que estaba determinada por el número de indios que recibían como trabajadores (Actas, 1970, t. 1, p. 74).

${ }^{30}$ Repartimiento de mano de obra. 17 de mayo de 1621. Tierras y Aguas. 2da. colección. Vol. 356, f. 74v. AIPG, México.

${ }^{31}$ Molienda de trigo por parte de los indígenas de Atotonilco El Alto. 3 de noviembre de 1674. Libros de gobierno. Vol. 2, exp. 232, fs. 306f-307f. AIPG, México.

\section{(ㅇ)(1) $\$$}


Las actas de Cabildo muestran a unos regidores que previendo una gran necesidad de pan ante las malas cosechas de trigo, salen en búsqueda del preciado grano comprándolo en las distintas haciendas de la comarca. ${ }^{32}$

La fuente oficial de esa institución nos habla de las medidas que se tomaron para controlar el precio de venta del trigo y del pan, ya que debido a su carestía este aumentaba considerablemente de un año a otro. En 1605 la fanega costaba 16 reales, pero en el siguiente la falta del mismo obligó a tasarla en 22 reales y así se mantuvo hasta 1610 cuando se rebajó a $20 .{ }^{33} \mathrm{~A}$ partir de 1618 el Cabildo instauró el sistema de visitas a las tiendas de la ciudad con el objetivo de vigilar los precios del pan, trigo y harina, modificándolos cuando consideraba que eran muy elevados, permitiendo sólo moderadas ganancias a los vendedores (Actas, 1970, t. 1, p. 192). Al menos estas y otras medidas adoptadas por los regidores fueron refutadas por otras autoridades y aun los mismos miembros del Ayuntamiento se vieron forzados a reconocer, años después, que no habían funcionado como más adelante veremos.

Lo que sostengo en este artículo es que es muy probable que los habitantes de Guadalajara sufrieran constantemente de la escasez de trigo y harina pero no por la falta de cosechas ni a la mala conservación del grano, esta se debió a la existencia de un sistema voraz de acaparamiento por parte de los hacendados y comerciantes que actuaban en contubernio con los regidores de esa ciudad para luego revenderlo a precios elevados. Desde 1606 el fiscal de la Audiencia de Guadalajara había señalado que el Ayuntamiento estaba controlado por un grupo de ricos hacendados que se confederaban entre sí para establecer un monopolio en torno al abasto de víveres (Chevalier, 1999, pp. 261-262).

La esencia de ese problema fue la falta de una alhóndiga en la ciudad donde se concentraran todas las semillas para venderlas a precios justos y evitar la reventa. Aunque durante el primer tercio del siglo xvir existió una, los miembros del Cabildo de Guadalajara la quitaron bajo el argumento de que ya tenían el estanco de vinos de coco y mezcal que le generaba buenos ingresos al ramo de propios. ${ }^{34}$ Sólo hasta que se suprimió ese estanco en 1652 ,

${ }^{32}$ Al menos así ocurrió en los años de 1611 y 1612 en donde se tuvieron que comprar 2000 y 1000 fanegas, respectivamente para paliar la necesidad de los pobres (Actas, 1970, t. 1 , pp. 107-108 y 118).

${ }^{33}$ La rebaja de dos reales se debió a que se había autorizado que los labradores cobraran esa cantidad por concepto de fletes, pero a partir de 1610 se estableció que los vendedores debían de absorber ese gasto (Actas, 1970, t. 1, p. 71).

${ }^{34} \mathrm{El}$ origen y funcionamiento de esta primera alhóndiga se desconoce. Según el cronista del siglo xviII Matías de la Mota Padilla, esta se fundó en 1662 cuando el presidente y gobernador de Nueva Galicia ordenó su instalación y destinó las entradas al ramo de propios

\section{(ㅇ)(1) $(3$}


los regidores se mostraron preocupados e interesados para que la ciudad contara con una alhóndiga (como la tenían la ciudad de México, Zacatecas, Puebla y San Luis Potosí). Hasta entonces les preocupó la regatonería y el alza en los precios del trigo, harina y pan. Tuvieron que reconocer que ante la falta de un almacén público, todos los trajinantes paraban en casas ubicadas en los pueblos de Mexicaltzingo y Analco, justo a las afueras de la ciudad, donde los ricos mercaderes les compraban todos los géneros para luego revenderlos. Tuvieron que aceptar que el precio del pan cocido que habían fijado en 32 onzas por un real no se respetaba, por lo que impusieron una multa de diez pesos y el comiso del pan a quien no lo vendiera al precio estipulado (Actas, 1970, t. 2, pp. 235-236).

No fue sino hasta fines de 1672 cuando el presidente y oidores de la Audiencia de Guadalajara autorizaron la erección de una nueva alhóndiga en la calle de San Agustín, a un costado de las casas de Cabildo, exactamente donde había estado funcionando la anterior. Se estableció el pago del derecho de alhondigaje en dos reales por cada carga de harina y uno por la de maíz. ${ }^{35}$ Una vez funcionando la alhóndiga, el Cabildo de Guadalajara no se hizo cargo de la administración, sino que subastó el derecho a particulares, debiendo contar con el visto bueno del presidente de la Audiencia. Para 1688, el contrato de arrendamiento fue por 260 pesos al año, para 1699 había aumentado a 350 pesos. Todavía en 1718 la administración de ella estaba en manos de particulares. ${ }^{36}$

\section{LISTA DE REFERENCIAS}

Actas de cabildos de la ciudad de Guadalajara (1970). Guadalajara: Ayuntamiento de Guadalajara/Instituto Jalisciense de Antropología e Historia/INAH.

de la ciudad; pero al mismo tiempo reconocía que no había encontrado pruebas de ello (Mota Padilla, 1973, p. 338). Lo que es cierto es que al menos en 1637 existía una pues en ese año, el Cabildo de la ciudad aceptó destinar doce pesos de lo que ingresaba a la alhóndiga para los negros y mulatos que danzaban en la fiesta de Corpus Cristi (Actas, 1970, t. 2, p. 13).

${ }^{35}$ Funcionamiento de la alhóndiga de Guadalajara. 9 de enero de 1672. Real Audiencia de Guadalajara. Ramo Civil 12-8-163. вPEj, México.

${ }^{36}$ Administración de la alhóndiga de Guadalajara. 30 de diciembre de 1688. José López Ramírez. Vol. 5, f. 262fv. AIPG, México; Postura para administrar la alhóndiga de Guadalajara. 2 de febrero de 1699. Real Audiencia de Guadalajara. Bienes de Difuntos. Exp. 216-202237. вреј, México.

\section{(ㅇ)(1) $\$$}


Acuña, R. (ed.) (1988). Relaciones geográficas del siglo xvi. Nueva Galicia. México: UnAm. Arregui, D. L. de (1980). Descripción de la Nueva Galicia. Siglo XVII. Guadalajara: Unidad Editorial del Gobierno del Estado de Jalisco.

Bakewell, P. J. (1984). Minería y sociedad en el México colonial: Zacatecas (1546-1700). México: FCE.

Berthe, J.-P. (1994). Introducción a la historia de Guadalajara y su región. En J.-P. Berthe (comp.), Estudios de historia de la Nueva España. De Sevilla a Manila (pp. 171184). México: Universidad de Guadalajara/Centre Français d'Etudes Mexicaines et Centroaméricaines.

Berthe, J.-P., Calvo, T. y Jiménez Pelayo, Á. (2000). Sociedades en construcción. La Nueva Galicia según las visitas de los oidores (1606-1616). Guadalajara: Universidad de Guadalajara/Centre Français d'Etudes Mexicaines et Centroaméricaines.

Borah, W. (1994). Tendencias de precios de bienes de tributo real en la Nueva Galicia, 15571598. Guadalajara: El Colegio de Jalisco/El Colegio de Michoacán.

Calvo, T. (1987). Guadalajara, Capitale provinciale de l'Occident mexicain au xvIIe siècle. (Tesis de doctorado). Ecole des Autes Etudes en Sciences Sociales, París.

Calvo, T. (1992a). Guadalajara y su región en el siglo XVII. Población y economía. Guadalajara: Ayuntamiento de Guadalajara.

Calvo, T. (1992b). Poder, religión y sociedad en la Guadalajara del siglo xviI. Guadalajara: Ayuntamiento de Guadalajara/Centre Francais d'Etudes Mexicaines et Centraméricaines.

Calvo, T. (1997). Por los caminos de Nueva Galicia: transportes y transportistas en el siglo XVII. Guadalajara: Universidad de Guadalajara/Centre Francais d'Etudes Mexicaines et Centraméricaines.

Chevalier, F. (1999). La formación de los latifundios en México. Haciendas y sociedad en los siglos XVI, XVII y XVIII. México: FCE.

Enciso Contreras, J. (1998). Cedulario de Zacatecas, 1554-1596. Zacatecas, Oñati, España: Ayuntamiento de Zacatecas/Facultad de Derecho-Universidad Autónoma de Zacatecas/Ayuntamiento de Oñati.

García Martínez, B. (2005). Los pueblos de la sierra. El poder y el espacio entre los indios del norte de Puebla hasta 1700. México: Colmex.

Gibson, Ch. (1996). Los aztecas bajo el dominio español 1519-1810, México: Siglo XXI Editores.

Gómez Serrano, J. (2006). Un mayorazgo sin fundación. La familia Rincón Gallardo y su latifundio de Ciénega de Mata, 1593-1740. Aguascalientes: Instituto Cultural de Aguascalientes/Universidad Autónoma de Aguascalientes.

\section{(ㅇ)(1) $\$$}


González Navarro, M. (1953). Repartimientos de indios en Nueva Galicia. México: Museo Nacional de Historia-INAH.

Iguíniz, J. B. (1971). Acusación contra el doctor Santiago de Vera, presidente de la Real Audiencia de Guadalajara, enviada al rey Don Felipe II por Jerónimo Conde, alguacil mayor y regidor perpetuo de Guadalajara [documento presentados por...]. Estudios de Historia Novohispana, IV, 187-213.

Jiménez Pelayo, Á. (1989). Condiciones del trabajo de repartimiento indígena en la Nueva Galicia en el siglo xvir. Historia Mexicana, XxxVIII(3), 455-470.

Jiménez Vizcarra, C. (1978). Indice del Archivo del Juzgado General de Bienes de Difuntos de la Nueva Galicia, siglos XVI y XVII. México: INAH.

Lancaster Jones, R. (1974). Haciendas de Jalisco y aledaños, 1506-1821. Guadalajara: Ediciones de Nacional Financiera.

López de Velasco, J. (1971). Geografía y descripción universal de las Indias. Madrid: Ediciones Atlas.

Mathes, M. (1976). Piratas en la costa de Nueva Galicia en el siglo xviI. Guadalajara: Librería Font.

Mota Padilla, M. de la (1973). Historia de la Nueva Galicia en la América septentrional. Guadalajara: Universidad de Guadalajara/Instituto Jalisciense de Antropología e Historia.

Mota y Escobar, A. de la (1993). Descripción geográfica de los reinos de Nueva Galicia, Nueva Vizcaya y Nuevo León. Guadalajara: Universidad de Guadalajara/Instituto Jalisciense de Antropología e Historia/Unidad Editorial del Gobierno del Estado de Jalisco.

Pacheco, J. y Cárdenas F. (comps.) (1865). Testimonio de la real cédula sobre el buen tratamiento de los indios, 1532. En Colección de documentos inéditos relativos al descubrimiento, conquista y colonización de las posesiones españolas en América y Oceanía, sacados en su mayor parte del real archivo de Indias (vol. xIV). Madrid: Imprenta de Manuel B. Quirós.

Peña, J. F. de la (1983). Oligarquía y propiedad en la Nueva España, 1550-1624. México: FCE.

Tello, Fray A. (1968). Crónica miscelánea y conquista espiritual y temporal de la Santa Provincia de Xalisco en el Reino de la Nueva Galicia (6 tt.). Guadalajara: Gobierno de Jalisco/Universidad de Guadalajara/INAH.

Van Young, E. (1989). La ciudad y el campo en el México del siglo XVIII: la economía rural de la región de Guadalajara. 1675-1820. México: FCE.

Zavala, S. (1987). El servicio personal de los indios en la Nueva España, 1576-1599 (tt. 2-3). México: Colmex/El Colegio Nacional.

\section{(ㅇ)(1) $(3$}




\section{OTRAS FUENTES}

Archivos

AGN Archivo General de la Nación, México.

AGI Archivo General de Indias, Sevilla, España.

AHAg Archivo Histórico del Arzobispado de Guadalajara, México.

AIPG Archivo de Instrumentos Públicos de Guadalajara, México.

вPEj Biblioteca Pública del Estado de Jalisco, México.

\section{Bibliografía}

García Icazbalceta, J. (comp.) (1971). Colección de documentos para la historia de México (2 vols.). México: Editorial Porrúa.

Gerhard, P. (1996). La frontera norte de la Nueva España. México: UNAM.

Tanck de Estrada, D. (2005). Atlas ilustrado de los pueblos de indios Nueva España, 1800.

México: El Colegio de México/El Colegio Mexiquense/Comisión Nacional para el Desarrollo de los Pueblos Indígenas/Fomento Cultural Banamex. 